\title{
A Nutritional Study on Weight Status among Urban Male High School Students and Its Related Determinants in Urmia, IRAN
}

\author{
Fatemeh Esmaeili Shahmirzadi ${ }^{1}$, Arash Rashidi ${ }^{2}$, Saeid Ghavamzadeh ${ }^{3} *$ \\ 1- Dept.of Nutrition Sciences, Faculty of Medicine, Urmia University of Medical Sciences, Nazloo highway, Urmia, Iran. \\ 2- Dept.of Nutrition Research, National Nutrition and Food Technology Research Institute, Faculty of Nutrition Sciences and Food Technology, Shahid \\ Beheshti University of Medical Sciences, Tehran, Iran. \\ 3- Food and Beverages Safety Research Center, Urmia University of Medical Sciences, Urmia, Iran.
}

\section{A B S T R A C T}

Background and Objectives: Several studies have so far been carried out to determine the prevalence of overweight and obesity among Iranian children but few studies have investigated the relationship between eating habits, socio-demographic differentials and obesity in these children. So, this study tried to assess the body weight status among the urban high school boy students of Urmia, Iran.

Materials and Methods: In this cross-sectional study, we measured weight, height and BMI of 1026 boy students with an age range of 15 to 19 years by multi-stage sampling. Then a questionnaire was completed based on their dietary habits and behaviors related to their physical activity. Overweight and obesity were defined based upon the World Health Organization's growth charts. Statistical analysis was fulfilled by estimating absolute and relative frequencies.

Results: Underweight prevalence in the studied population was 9.84\% (95\% CI: $8.49 \%-10.72 \%$ ). The prevalence of overweight and obesity among the studied students was $12.77 \%$ (95\% CI: $11.89 \%-13.3 \%$ ), and 5.07\% (95\% CI: 4.5\%-5.9\%), respectively. Factors significantly correlated with the participants' body weight were the frequency of energy dense foods intake during a week $(\mathrm{P}<0.001)$, duration of computer use per day $(\mathrm{P}<0.01)$, and the kind of their schools $(\mathrm{P}<0.05)$. No significant association was found between other studied dietary variables (such as the time spent for eating over 24-hours, and breakfast eating times per week) and overweight/obesity.

Conclusions: In the present study, we found that two changeable parameters (i.e. the number of times for intake of energy dense foods during a week, and working with computers) could influence the 15-19 years old school boys' body weight in the study region.

Keywords: Prevalence, Underweight, Overweight, Obesity, High school boys

\section{Introduction}

Adolescent obesity is associated with many adverse health problems, including hypertension, dyslipidemia, left ventricular hypertrophy, atherosclerosis, metabolic syndrome, type 2 diabetes, sleep apnea, and non-alcoholic fatty liver disease, as well as psychological effects such as depression and emotional trauma (1).

Obesity is defined as a condition of abnormal or excessive fat accumulation in the adipose tissue to the extent that health is impaired $(2,3)$. In spite of institutional prevention efforts even in the developing countries, the prevalence of obesity has increased worldwide dramatically in the last few decades (1). Obesity has been identified as an independent risk factor for cardiovascular diseases (CVDs); it is associated with reduced life expectancy due to an increased risk of mortality and morbidity.

Healthy eating behavior during adolescence is a fundamental prerequisite for physical growth, psychosocial development and cognitive 
performance, as well as for prevention of diet-related chronic diseases in adulthood. It has been shown that adult overweight is associated with CVDs, hypertension, type 2 diabetes, atherosclerosis, gout, arthritis and some of the malignancies (4- 6).

Furthermore, many of the studies detected that childhood and adolescence obesity is correlated with adulthood mortality $(4,6,7)$. In addition, psychological disorders such as depression occur with an increased frequency in obese children (8).

The last two decades of the previous century have affirmed impressive rise in health care costs because of obesity and related issues among children and adolescents (9). It has been estimated that the prevalence of obesity and overweight in the 2000s among Iranian children and adolescents was $5.1 \%$ and $10.8 \%$, respectively (10). In a more recent national study, it was indicated that $17.3 \%$ of the students at the age range of $10-19$ years $(17.3 \%$ of girls and $17.5 \%$ of boys) were underweight, and $17.7 \%$ (15.5\% of girls and $19.9 \%$ of boys) were overweight or obese (11). Obesity in adults is not easy to be treated; it is often correlated with obesity during childhood $(1,4)$.

Prevalence rates and trends in thinness and overweight/obesity among children and adolescents at national and sub-national levels are also most important issues, especially to nutrition policy-makers (12).

The main aim of the present study is to provide baseline information on the prevalence of thinness and overweight in Urmia's children and adolescents. Also, for the first time, their predictors are calculated for geographical comparisons and descriptions of time trends.

\section{Materials and Methods}

In this descriptive cross-sectional study, we selected 17 secondary schools from the 102 existing schools of Urmia City, Iran. This city has been divided into two educational regions by the Ministry of Education. The city possesses governmental and private high schools in each region. According to the official statistics, the city composes 44 governmental and 58 private males' schools. Totally, 17 schools were selected from both regions, and altogether 1026 students were chosen with an age range of 15-19 years by multi-stage sampling.

At the first phase, a pilot study with 45 students at the same age range was conducted to test the field actions, and to improve the validity and reliability of the questionnaire. The field research was started in October 2006 and completed at the end of 2006 by trained field workers who were weighing the students, measuring their stature and filling the questionnaires.

To weigh the students, we used a digital scale made by TEFAL Company (with 100 gram accuracy). We asked the students to take off their overcoat and to stand on scale with no movement; then we read and recorded their weight on the questionnaire. A BMI over $85^{\text {th }}$ centile of BMI curve indicated overweight and over $95^{\text {th }}$ centile of BMI curve was considered as obesity. BMI through the $5^{\text {th }}$ to $85^{\text {th }}$ centile was taken into account as normal $(6,13)$. As the same way, BMI less than the $5^{\text {th }}$ centile were defined as underweight (14).

To measure the students' height, we applied a tailor's tape installed vertically on the wall of the classroom. The students took off their shoes, and stood in front of the tape with heels together and toes apart; then we set their head position on Frankfort horizontal plane, measured their length by a square, and recorded them on the questionnaire (with 1 millimeter accuracy).

The trained field workers were three persons. The first person was weighing the students, the second one was measuring their length, and the third one was interviewing face-to-face and filling the questionnaires. The interviewer explained each of the questions to the students, and then ticked the question. The students were asked about some variables possibly affecting their body weights including nutrition in the first year of life, the educational level of their parents, their birth time, the occupational status of their parents, weight status of the father and mother, weekly meals fed as fast foods, breakfast eating habits, and finally, being active or inactive in a usual day (including reading duration, sleep duration, daily duration of computer use, TV watching duration, class time, sedentary games and walking duration).The studied dietary variables included the time spent for eating over 24-hours, and the frequency of eating a battery of energy dense foods including potato chips, fried fast foods, pizza, butter, nuts and seeds over a given week. The students were allowed to call their mothers and answer the questions when they did not know any of the questions.

Ethical considerations were met according to the Nutrition and Food Sciences Research Journal policy. Data were analyzed by the SPSS software (version 16.0, SPSS Inc., Chicago, IL, USA). Quantitative variables are expressed as mean \pm standard deviation (SD) and categorical data as percentage. Pearson's Chi-square test was applied to do the statistical analysis (with 95\% confidence intervals). We applied 
Student's t-test to examine the equality of the means. We calculated the crude odds ratio (OR) by using logistic regression test to find the degree of association between various risk factors and obesity. All variables within the univariate analysis were presented to the multiple model by using stepwise method. The results of logistic regression analysis are presented by OR and 95\% confidence interval. A Pvalue $<0.1$ was considered as statistically significant.

\section{Results}

The total number of the students was 1026 boys; of which 529 students belonged to Region 1, and 497 students to Region 2 of Urmia City with the age range of 14-19 years. The mean of BMI for all of the participants was $21.46 \pm 2.03$ (95\% CI: 19.23-22.89). This study revealed that the prevalence of overweight and obesity among the studied students was 141 (12.77\%, 95\% CI: $11.46 \%-14.02 \%)$, and 52 (5.07\%, 95\% CI: $4.12 \%-5.91 \%)$, respectively. The prevalence of underweight was $108(9.84 \%, 95 \%$ CI: $8.49 \%$ $10.72 \%)$ (Figure1). The remind participants $(\mathrm{n}=742)$ were at the normal range of BMI curve $(72.32 \%, 95 \%$ CI: 71.03-73.86).

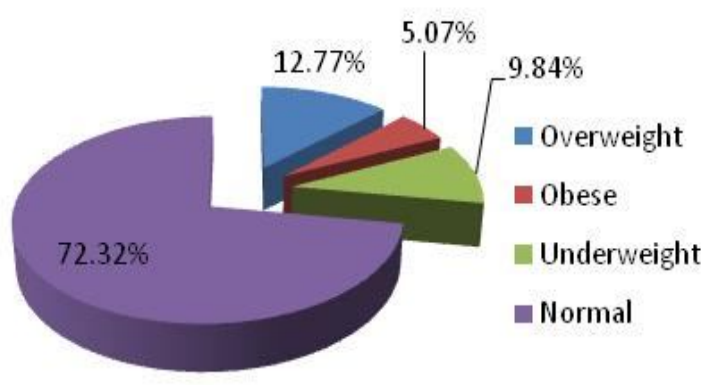

Figure 1. Prevalence of underweight, overweight and obesity among Urmia urban high school boys $(n=1026)$; Iran

Factors that were significantly associated with the participants' body weight included duration of computer use per day $(\mathrm{P}<0.001)$ (Table 1), the number of intake of calorie dense foods per week $(\mathrm{P}<0.01)$ (Table 2$)$, family size $(\mathrm{P}<0.01)$, and the kind of their schools $(\mathrm{P}<0.05)$. As a result, obese plus overweight $(\mathrm{OB}+\mathrm{OW})$ students have smaller family size compared to non-OB+OW students (i.e. $2.26 \pm 1.12$ vs. $3.83 \pm 1.63)$.

Table 1. Absolute and relative frequency of the participants' weight status concerning duration of computer use per day, Urmia, Iran

\begin{tabular}{|c|c|c|c|c|c|c|c|c|c|c|}
\hline \multirow{3}{*}{ Weight status } & \multicolumn{10}{|c|}{ Duration of computer use per day (hrs.)* } \\
\hline & \multicolumn{2}{|c|}{$<1$} & \multicolumn{2}{|c|}{$1-<2$} & \multicolumn{2}{|c|}{$2-<3$} & \multicolumn{2}{|c|}{$\geq 3$} & \multicolumn{2}{|c|}{ Total } \\
\hline & $\mathrm{n}$ & $\%$ & $\mathrm{n}$ & $\%$ & $\mathrm{n}$ & $\%$ & $\mathrm{n}$ & $\%$ & $\mathrm{n}$ & $\%$ \\
\hline Under weight & 19 & 18.81 & 42 & 41.59 & 29 & 28.71 & 11 & 10.89 & 101 & 100 \\
\hline Over weight & 15 & 11.45 & 14 & 10.69 & 43 & 32.82 & 59 & 45.04 & 131 & 100 \\
\hline Obese & 6 & 11.54 & 7 & 13.46 & 21 & 40.38 & 18 & 34.62 & 52 & 100 \\
\hline Normal & 104 & 14.02 & 118 & 15.90 & 312 & 42.05 & 208 & 28.03 & 742 & 100 \\
\hline
\end{tabular}

* Chi square test $(\mathrm{P}<0.001)$

Table 2. Absolute and relative frequency of the subjects' weight status concerning times for intake of energy dense foods per week, Urmia, Iran

\begin{tabular}{|c|c|c|c|c|c|c|c|c|c|c|c|c|}
\hline \multirow{3}{*}{ Weight status } & \multicolumn{12}{|c|}{ Frequency of intake of energy dense foods per week $*$} \\
\hline & \multicolumn{2}{|c|}{$<2$} & \multicolumn{2}{|c|}{$2-<3$} & \multicolumn{2}{|c|}{$3-<4$} & \multicolumn{2}{|c|}{$4-<5$} & \multicolumn{2}{|c|}{$\geq 5$} & \multicolumn{2}{|c|}{ Total } \\
\hline & $\mathrm{n}$ & $\%$ & $\mathrm{n}$ & $\%$ & $\mathrm{n}$ & $\%$ & $\mathrm{n}$ & $\%$ & $\mathrm{n}$ & $\%$ & $\mathrm{n}$ & $\%$ \\
\hline Underweight & 17 & 16.83 & 32 & 31.68 & 19 & 18.81 & 21 & 20.79 & 12 & 11.89 & 101 & 100 \\
\hline Overweight & 8 & 6.11 & 14 & 10.69 & 38 & 29.01 & 48 & 36.64 & 23 & 17.55 & 131 & 100 \\
\hline Obese & 2 & 3.85 & 6 & 11.54 & 20 & 38.46 & 18 & 34.61 & 6 & 11.54 & 52 & 100 \\
\hline Normal & 28 & 3.78 & 89 & 11.99 & 309 & 41.64 & 249 & 33.56 & 67 & 9.03 & 742 & 100 \\
\hline
\end{tabular}

* Chi square test $(0.01)$ 
The $\mathrm{M} \pm \mathrm{SD}$ of duration of computer use per day for obese and overweight $(\mathrm{OB}+\mathrm{OW})$ and underweight students was $3.46 \pm 1.17$ and $1.46 \pm 0.82$, respectively $(\mathrm{P}<0.001)$.

The association analysis (Tables $3 \& 4$ ) revealed that the mothers' educational level and the kind of schools the students studied there are the most important determinants for becoming overweight and/or obese.

We could not detect a statistically significant difference between $\mathrm{OB}+\mathrm{OW}$ students and the others for the factors of time spent for eating over 24-hours, educational status of their mothers, feeding pattern in the infancy (breastfed or non-breastfed) and breakfast eating times per week.

Table 3. Association between independent factors and obesity plus overweight in univariate logistic regression model, Urmia, Iran

\begin{tabular}{|c|c|c|c|c|}
\hline Independent factors & $\begin{array}{l}\mathrm{OB}+\mathrm{OW}^{\S} \\
(\mathrm{n}=183)\end{array}$ & $\begin{array}{c}\text { Normal } \\
(\mathrm{n}=742)\end{array}$ & Crude OR & $95 \% \mathrm{CI}$ \\
\hline $\mathrm{BMI}\left(\mathrm{kg} / \mathrm{m}^{2}\right) *$ & $26.62 \pm 2.96$ & $22.34 \pm 2.12$ & 1.00 & $1.00-1.00$ \\
\hline Computer using duration hrs/day $*$ & $2.12 \pm 0.45$ & $0.92 \pm 0.34$ & 2.24 & $1.66-3.69$ \\
\hline TV watching duration hrs/day $*$ & $2.34 \pm 0.48$ & $2.16 \pm 0.39$ & 0.93 & $0.89-1.12$ \\
\hline Reading duration hrs/day $*$ & $2.68 \pm 1.02$ & $2.87 \pm 0.79$ & 0.99 & $0.91-1.09$ \\
\hline Physical games \& walking duration hrs/day * & $0.89 \pm 0.34$ & $1.32 \pm 0.49$ & 0.69 & $0.56-0.82$ \\
\hline Sleep duration $\mathrm{hrs} /$ day $*$ & $7.54 \pm 1.22$ & $7.64 \pm 1.92$ & 0.93 & $0.88-1.16$ \\
\hline \multicolumn{5}{|l|}{ Family size $* *$} \\
\hline$\leq 4$ & $118(64.48)$ & $414(55.79)$ & Ref & \\
\hline$\overline{5}-6$ & $46(25.14)$ & $217(29.24)$ & 0.89 & $0.82-1.09$ \\
\hline$\geq 7$ & $19(10.38)$ & $111(14.98)$ & 0.77 & $0.69-1.14$ \\
\hline \multicolumn{5}{|l|}{ Kind of school ** } \\
\hline Governmental & $78(42.63)$ & $516(69.54)$ & Ref & \\
\hline Non-governmental & $105(57.37)$ & $226(30.46)$ & 3.89 & $1.26-6.67$ \\
\hline \multicolumn{5}{|l|}{ Mother's educational level $* *$} \\
\hline Primary & $12(6.56)$ & 293(39.49) & Ref & \\
\hline Secondary & $65(35.52)$ & $254(34.23)$ & 2.34 & $1.79-4.98$ \\
\hline University degrees & $106(57.92)$ & $195(26.28)$ & 12.69 & $8.45-21.23$ \\
\hline \multicolumn{5}{|l|}{ Breastfeeding until 12 months $* *$} \\
\hline Yes & $86(49.99)$ & $389(52.43)$ & Ref & \\
\hline No & $97(53.01)$ & $353(47.57)$ & 0.89 & $0.69-1.32$ \\
\hline \multicolumn{5}{|l|}{ Breakfast eating times/week $* *$} \\
\hline$\leq 3$ & $32(17.49)$ & 103(13.88) & Ref & \\
\hline $4-5$ & $86(46.99)$ & $572(77.09)$ & 0.68 & $0.57-0.92$ \\
\hline$\geq 6$ & $65(35.52)$ & $67(9.03)$ & 1.45 & $1.22-2.98$ \\
\hline \multicolumn{5}{|l|}{ Fast foods eating times /week $* *$} \\
\hline$\leq 3$ & $125(68.31)$ & $534(71.96)$ & Ref & \\
\hline $4-6$ & $38(20.76)$ & $141(19.01)$ & 0.94 & $0.84-1.87$ \\
\hline$\geq 6$ & $20(10.93)$ & $67(9.03)$ & 0.98 & $0.89-1.49$ \\
\hline \multicolumn{5}{|l|}{ Eating energy dense foods times/week $* *$} \\
\hline$<2$ & $10(5.46)$ & $28(3.77)$ & Ref & \\
\hline $2-4$ & $78(42.62)$ & $398(53.63)$ & 0.58 & $0.48-0.88$ \\
\hline$>4$ & $95(51.92)$ & $316(42.58)$ & 1.98 & $1.34-3.54$ \\
\hline
\end{tabular}

$*$ Quantitative factors explained as mean $\pm \mathrm{SD} ; * *$ Qualitative factors explained as $\mathrm{N}(\%) ; \S$ Obesity and overweight

Table 4. Association between independent variables and obesity in multiple logistic regression model after adjustment of effective variables, Urmia, Iran

\begin{tabular}{lcc}
\hline Variables & Adjusted OR & $95 \%$ CI * \\
\hline Mother's educational level ** & & \\
$\quad$ Primary & Ref & \\
Secondary & 1.98 & $1.56-3-44$ \\
$\quad$ University degrees & 4.89 & $2.76-7.98$ \\
Kind of school ** & & \\
$\quad$ Governmental & Ref & \\
$\quad$ Non-governmental & 2.34 & $1.75-4.64$ \\
\hline * Adjusted for breakfast eating times/week; eating energy dense foods \\
times/week; computer using duration
\end{tabular}

\section{Discussion}

The findings represented here indicated that the percent of overweight and obesity was 12.77 and 5.07, respectively (17.84\% in total). This shows a high prevalence of $\mathrm{OB}+\mathrm{OW}$ in the study population so that around one sixth to one fifth of the students were suffering from the overweight and/or obesity adverse outcomes.

In a recent comprehensive study (CASPIAN study), data of 5528 students (2726 girls, $69.37 \%$ urban, mean age $14.7 \pm 2.4$ years) were completed 
and reported. Overall, $17.3 \%$ (17.3\% of girls and $17.5 \%$ of boys) were underweight, and $17.7 \%$ ( $15.5 \%$ of girls and $19.9 \%$ of boys) were overweight or obese (11).

In a study conducted in high-school boys aged 14-18 years in Sistan and Baluchistan Province, Islamic Republic of Iran, it was shown that the prevalence of underweight, overweight and obesity was $16.2 \%, 8.6 \%$ and $1.5 \%$, respectively (15). The incidence of underweight prevalence is higher than that of our study but the prevalence of obesity and overweight is lower than that of ours. The criteria used in the study were the same as ours. It is to be noted that Sistan and Baluchistan Province is one of the most deprived provinces in Iran mostly due to its warm, dry and droughty climate. The authors of the study had been mentioned that their findings regarding the underweight prevalence were higher than those of other parts of Iran. Our study revealed that the kind of the schools was correlated with the participants' weight status significantly. The kind of schools could be taken into account as one of the indices for socioeconomic status of the households (16). Then these different figures in our study and the mentioned study may be due to the different socioeconomic status of the study populations.

In another research (in Hamedan City, Iran), the above figures were $2.55 \%$ and $3.5 \%$, respectively (totally 6.65\%) (17). The cut-off points used to define the overweight and obesity in Hamedan study were not the same as ours. Also the population of the mentioned study included both the boy and boy students $(\mathrm{n}=2000)$.

The results of a meta-analysis study regarding the prevalence of obesity (and not overweight) in Iran (18) showed that overall prevalence was $5.5 \%$ for under 18 years old population. The obesity prevalence in boys under 18 years of age was $4.58 \%$. This study included 62 provincial studies with two studies in East Azerbaijan, the nearest province to Urmia as the largest city in West Azerbaijan. On the other hand, ethnic differences were not taken into account.

In Canadian boys aged 12 to 19 years, the prevalence of overweight and obesity was estimated s $3 \%$ and $10 \%$, respectively (19). The defined cutoffs in this study were also not identical with our study.

In the current study, the time of eating energy dense foods per week was associated with the weight status of the children $(\mathrm{P}<0.01)$. As a result, the more frequent the students had intake of energy dense foods per week, the more chance they had to be obese. In a case-control study conducted on 114 students aged 6-12 years, the authors confirmed the role of an unhealthy diet, notably calorie-dense snacks, in childhood obesity (20).

In a cross-sectional study on boys and girls aged 6-18 years conducted in Bahrain, it was revealed that high sugar consumption, low intake of dietary fiber and energy dense foods rich in fats and dietary cholesterol by many Bahraini children are the two likely factors in increasing their risk of obesity and cardiovascular diseases in later life (21).

In a study conducted in the United States, it was found that boys who had average weight and viewed themselves as either very underweight or overweight reported significantly higher levels of depressive symptoms compared to boys who accurately viewed their weight as average $(n=2,139)$. This effect remained constant over the 13-year study period (22). This finding demonstrates that distortions in body image, particularly extreme distortions, are risk factors for elevated depressive symptoms among adolescent boys, and persist into early adulthood.

Working with computer is another variable affecting the weight status in our study. A study conducted in Iran (23) detected that the time spent on watching TV was associated with an increased risk of obesity and overweight. Tremblay et al. suggested that both organized and unorganized sport and physical activities are negatively associated with being overweight (10-24\% reduced risk) or obese (23-43\% reduced risk), while TV watching and computer use are risk factors for being overweight (17-44\% increased risk) or obese (10-61\% increased risk) (19). They concluded that first physical activity and sedentary behaviors partially account for the association of high socioeconomic status, and secondly two-parent family structure increases the likelihood of being overweight or obese.

Wake and coworkers in Australia found that child mean BMI z-score was significantly related to TV watching $(\mathrm{P}<0.001)$, but not video game/computer time $(\mathrm{P}=0.09)$, and that they account for only 1 and $0.2 \%$ of total BMI variance, respectively (24). When parental BMI, parental education, number of sibling, food intake, organized exercise and general activity level were included, TV watching ceased to be significantly related to child BMI independently (25). They concluded that a small proportion of variance in child BMI was related to TV watching, but not video/game/computer time. In conclusion, our findings revealed two changeable parameters (i.e. the number of times for eating energy dense foods during a week, and working with computers) 
influence the high school boys' body weight in the study region.

It is worth accentuating that our study was designed by using a questionnaire based upon the long term memory of the subjects, which may not be an accurate way to achieve our purposes regarding some of the quantitative variables.

\section{Acknowledgement}

Thanks are due to the Research Vice-chancellor of Urmia University of Medical Sciences for providing the grant of the present project. In addition, we sincerely thank all the students and managers who helped us to carry out the study.

\section{Financial disclosure}

The authors declare no conflict of interest.

\section{Funding/Support}

This work was financially supported by the Vicechancellor of Urmia University of Medical Sciences.

\section{References}

1. Pratt CA, Stevens J, Daniels S. Childhood obesity prevention and treatment: recommendations for future research. Am J Prev Med 2008; 35(3): 249-252.

2. World Health Organization. Physical status: the use and interpretation of anthropometry. Report of a WHO Expert Committee. WHO Technical Report Series 1995; 854: 6-9.

3. Garrow JS. Obesity and related diseases. Edinburgh, Churchill Livingstone 1988. p. 1-16.

4. Ghassemi H, Harrison G, Mohammad K. An accelerated nutrition transition in Iran. Pub Health Nutr 2002; 5(1A):149-55.

5. Hoffman Dj. Obesity in developing countries: causes and implications. Food Nutragricul. 2001; 28:35-41.

6. Rotimi CN, Cooper RS, Atman SL. Distribution of anthropometric variables and the prevalence of obesity in population of West African origins: The intervention collaborative study on hypertension. Obs Res. 1995; 3 suppl.2:955-1025.

7. Felber IP, Achesson KJ, Tappy L. From obesity to dietetics. New York: John Willey \& sons; 1993:69-92

8. Badawi NS, Barakat AA, Sherbini SA, Fawzy HM. Prevalence of overweight and obesity in primary school children in Port Said city. Egyp Pediat Assoc Gaz. 2013; 61:31-36.

9. Raj M, Kumar RK. Obesity in children \& adolescents. Indian J Med Res. 2010 Nov; 132(5): 598-607.

10. Kelishadi R, Haghdoost AA, Sadeghirad B, Khajehkazemi R. Trend in the prevalence of obesity and overweight among Iranian children and adolescents: A systematic review and meta-analysis. Nutrition 2014;30:393-400.
11. Kelishadi R, Heshmat R, Motlagh ME, Majdzadeh R, Keramatian K, Qorbani M, et al. Methodology and Early Findings of the Third Survey of CASPIAN Study: A National School-based Surveillance of Students' High Risk Behaviors. Int J Prev Med. 2012 Jun; 3(6):394-401.

12. Lazzeri G, Rossi S, Pammolli A, Pilato V, Pozzi T, Giacchi MV. Underweight and overweight among children and adolescents in Tuscany (Italy). Prevalence and short-term trends. J Prev Med Hyg. 2008 Mar; 49(1):13-21.

13. World Health Organization. Obesity, prevention and managing the global epidemic, report of WHO consultation on obesity. Geneva: Tune; 1997: 30-34.

14. National Center for Health Statistics in collaboration with the National Center for Chronic Disease Prevention and Health Promotion, http://www.cdc.gov/ growthcharts/clinical_charts.htm

15. Montazerifar F, Karajibani M, Rakhshani F, Hashemi M. Prevalence of underweight, overweight and obesity among high-school boys in Sistanva Baluchistan. East Mediter Health J. 2009; 15:1293-300.

16. Hemmatinezhad MA, Rahmati MA, Manochehrinezhad M. Relationship between Social-Economic status of Family and Adolescents student Sport Participation. Ann Biol Res. 2012; 3 (8):4012-6.

17. Soheilifar J, Sadri G., The prevalence of obesity in primary students, Hamedan, Iran. J Hamedan Univ Med Sci. 1999; 7(2):15-22. [in Persian].

18. Mirzazadeh A, Sadeghirad B, Haghdoost AA, Bahrein F, Kermani MR. The Prevalence of Obesity in Iran in Recent Decade; a Systematic Review and Meta-Analysis Study. Iranian J Publ Health. 2009; 38(3):1-11.

19. Tremblay MS, Williams JD. Is the Canadian childhood obesity epidemic related to physical inactivity? Int J Obes Relat Meta Disord. 2003; 27(9):1100-5.

20. Baygi F, Qorbani M, Dorosty AR, Kelishadi R, Asayesh H, Rezapour A, et al. Dietary predictors of childhood obesity in a representative sample of children in north east of Iran. Zhongguo Dang Dai ErKeZaZhi. 2013; 15(7):501-8.

21. Gharib N, Rasheed P. Energy and macronutrient intake and dietary pattern among school children in Bahrain: a cross-sectional study. Nutr J. 2011;5(10):10-62.

22. Aaron J. Blashill and Sabine Wilhelm: Body Image Distortions, Weight, and Depression in Adolescent Boys: Longitudinal Trajectories Into Adulthood. Psychology of Men \& Masculinity. 2014, Vol. 15, No. 4, 445-451.

23. Ghavamzadeh S, Khalkhali HR, Alizadeh M. TV Viewing, Independent of Physical Activity and Obesogenic Foods, Increases Overweight and Obesity in Adolescents. J Health Popul Nutr. 2013;1(3):334-42.

24. Wake M, Hesketh K, Waters E. Television, computer use and body mass index in Australian primary school children. J Paediatr Child Health. 2003; 39(2):130-4.

25. Schwimmer JB. Managing overweight in older children and adolescents. Pediatr Ann Jan. 2004; 33(1):39-44. 